\title{
Effect of ambient temperature on the formation mechanism of PTFE liner transfer film of spherical plain bearings
}

\author{
Ming Qiu ${ }^{1,2,}{ }^{*}$, Kai-Wen Tian ${ }^{1}$, and Ya-Tao Zhang ${ }^{1}$ \\ ${ }^{1}$ School of Mechatronics Engineering, Henan University of Science and Technology, Luoyan 471003, PR China \\ ${ }^{2}$ Henan Collaborative Innovation Center for Advanced Manufacturing of Mechanical Equipment, Henan University of Science \\ and Technology, Luoyang 471003, PR China
}

Received: 4 November 2020 / Accepted: 29 January 2021

\begin{abstract}
The relationship between the formation of the transfer film and the tribological properties of the selflubricating spherical plain bearing was studied at the ambient temperature of $25-145^{\circ} \mathrm{C}$. The results show that the wear, friction coefficient and friction temperature increase of the spherical plain bearings all decreased first and then increased with the increase of the ambient temperature. The general trend is that the bearing has the most excellent anti-friction and wear resistance at $55-85^{\circ} \mathrm{C}$. An increase in ambient temperature will accelerate the formation speed of PTFE transfer film and shorten the running-in period of the bearing, but the ambient temperature above $85^{\circ} \mathrm{C}$ will shorten the duration of the PTFE transfer film, thus accelerating the bearing into the degradation period. The transfer film coverage of the liner after wear was characterized, and it was found that the transfer film coverage was the largest when the ambient temperature was $85^{\circ} \mathrm{C}$. The wear form of the bearing is mainly abrasive wear and adhesive wear, and the aramid fiber is more prone to adhesive wear. The anti-friction effect of the bearing is determined by the PTFE transfer film. Elevated ambient temperature can promote the formation of PTFE transfer film and enhance the antifriction effect, but if the ambient temperature is too high, the wear resistance of the PTFE transfer film will be reduced, thus reducing the friction reduction effect.
\end{abstract}

Keywords: Self-lubrication spherical plain bearing / ambient temperature / friction and wear / transfer film

\section{Introduction}

Self-lubricating spherical plain bearings are used in landing gears, wings and operating systems of airplanes, and steering and braking systems of vehicles. Its service performance is directly related to the safety of personnel and equipment [1]. The failure form of the fabric selflubricating spherical plain bearing is mainly the wear of the liner. The wear of the liner increases the gap between the inner and outer rings of the spherical plain bearing, which eventually leads to the failure of the spherical plain bearing $[2,3]$. Temperature, load and swing frequency are important factors affecting the wear resistance of polymer composites [4-7].

Ambient temperature will affect the lubricating characteristics of self-lubricating spherical plain bearings [8], which in turn will affect the life and reliability of the entire bearing. Therefore, it is necessary to investigate the influence law and mechanism of ambient temperature on

\footnotetext{
* e-mail: qiuming@haust.edu.cn
}

the performance of self-lubricating spherical plain bearings. New research methods and test equipment have provided great help for revealing the lubrication and friction and wear mechanisms of spherical plain bearings. PTFE exhibits excellent chemical resistance, low friction coefficient and high-temperature stability due to its unique molecular structure, so it is widely used in anti-friction and wear-resistant parts [9-12]. PTFE has been shown to transfer to a metal counter sample in as early as one sliding cycle [13-15].

Liang [16] tested a series of laser surface textures (dimples) aimed at improving bearing friction performance, and evaluated the effect on transfer film formation by surface analysis methods. It was found that the depth of the pits should match the thickness of the transfer film to achieve the beneficial effects of film formation, while the diameter and coverage of the texture need to be relatively small to avoid high levels of wear. Wang et al. [17] prepared a series of bronze/PTFE composite material transfer films on the surface of 45 \# steel and 2024 aluminum alloy substrate. The study found that as the filler content increases, the wear rate of the composite decreases, and the 
corresponding transfer film uniformity and wear resistance also increase. The lower the wear rate of the material, the better the wear resistance of the transfer film, and this correspondence is not affected by changes in the base material. Yang et al. [18] studied the tribological properties of self-lubricating spherical plain bearings under different temperatures, swing angles and loads. The results show that as the temperature, load and swing angle increase, the sensitivity of the wear rate to the load and swing angle increases, and leads to changes in wear patterns. References $[19,20]$ studied the friction and wear tests of PTFE/Nomex composite materials under different loads and ambient temperatures when graphite and $\mathrm{MoS}_{2}$ were used as fillers. The results show that the addition of graphite can effectively reduce the wear of PTFE/Nomex composite materials, while the addition of molybdenum disulfide is not conducive to improving the wear resistance of composite materials. The significant decreased in wear rate and coefficient of friction might be attributed to the formation of a thin and tenacious transfer film on the counter-surface. Yan et al. [21] used 3-aminopropyl triethoxysilane modified nano-graphite oxide sheet as a lubricating additive into the polyethersulfone (PES) matrix, and then carried out the wear test. The result shows compared with the virgin PES, the PES composite with the APTES-GO addition of $1.0 \mathrm{wt} \%$ exhibits a much lower friction coefficient and wear rate. This can be attributed to the homogeneous dispersion of APTES-GO within the PES matrix and strong interfacial adhesion between them, as well as the formation of uniform PES transfer film. Pitenis et al. [22] studied the friction-reducing mechanism of alumina additives on PTFE composites. The results show that the mechanical stress on the worn surface causes the PTFE chain to break, and in the presence of oxygen and water in the environment, carboxylic acid end groups are generated. These carboxylic acid end groups can chelate with bare metal on the steel surface and nucleate to form a transfer film. The resulting thin and strong PTFE transfer film protects the steel surface. These effects keep the friction coefficient and wear rate low and stable. References [23,24] evaluated the tribological properties of polyetherimide composite carbon fiber fabrics in different weft directions (plain weave, twill weave and satin weave) under low-amplitude vibration wear/fretting wear mode. Demirci and Düzcükoglu [25] studied the effect of sliding speed and load on the friction and wear of polyamide 66 , polyamide $66+18 \%$ polytetrafluoroethylene and polyamide $66+20 \%$ glass fiber $+25 \%$ polytetrafluoroethylene sliding bearing. It shows that the friction coefficient, friction temperature and wear rate are affected by pressure and speed, while the mechanical properties of PTFE are related to temperature, pressure and speed.

To deeply study the tribological performance and lubrication \& wear mechanism of the spherical plain bearing at ambient temperature, this paper uses the spherical plain bearing test system to study the tribological performance of the spherical plain bearing under different ambient temperatures. Scanning electron microscope (SEM), energy spectrometer (EDS) and laser scanning confocal microscope (LSCM) were used to analyze the

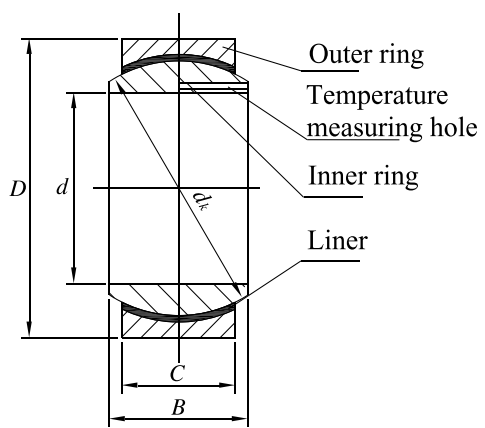

Fig. 1. Structure diagram of self-lubricating spherical plain bearing.

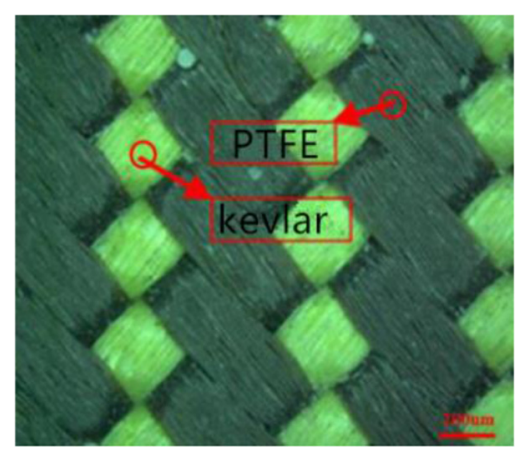

Fig. 2. Friction surface of fabric liner.

microscopic morphology and transfer film formation mechanism of the friction surface.

\section{Experiment object and methods}

\subsection{Experiment object}

The model of self-lubricating spherical plain bearing used in the test is GE30UK-2RS. Its structure is shown in Figure 1. The basic structural dimensions are: outer diameter $\mathrm{D}=47 \mathrm{~mm}$, outer ring width $\mathrm{C}=18 \mathrm{~mm}$, inner diameter $\mathrm{d}=30 \mathrm{~mm}$, and ball diameter $\mathrm{dk}=40.7 \mathrm{~mm}$, the inner ring width $\mathrm{B}=22 \mathrm{~mm}$. The self-lubricating liner of the test bearing is made of polytetrafluoroethylene (PTFE) fiber and aramid (Kevlar) fiber. The liner thickness is $0.3 \pm 0.01 \mathrm{~mm}$, and the mass per square meter is about $500 \mathrm{~g}$. The double-layer twill weave structure is used, so that the friction surface is mainly made of PTFE fiber with excellent lubricating performance, and the bonding surface is mainly made of aramid fiber with high strength and good bonding performance. The friction surface of the liner is shown in Figure 2, where the yellow fiber bundle is aramid fiber, and the dark brown is PTFE fiber. The liner and the inner spherical surface of the outer ring are bonded with a phenolic epoxy resin adhesive, and the inner ring is chrome plated. The thickness of the chrome-plated layer is $8-12 \mathrm{um}$, and the bearing clearance after assembly is $0.03-0.05 \mathrm{~mm}$. 


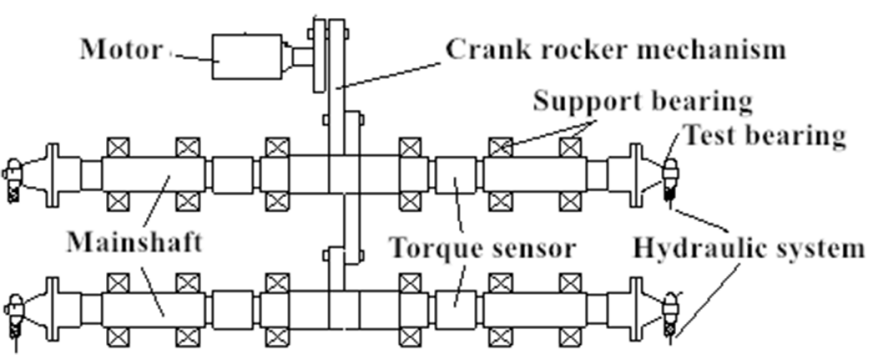

Fig. 3. Schematic diagram of the spherical plain bearing friction and wear tester.

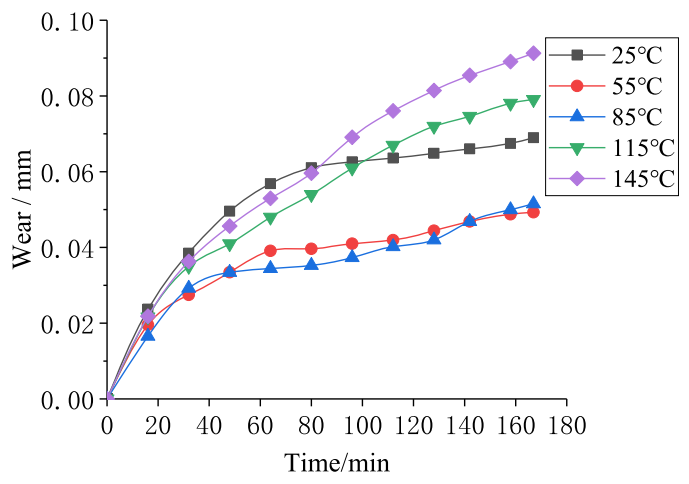

Fig. 4. Liner wear process.

Table 1. Friction and wear test scheme.

\begin{tabular}{lllll}
\hline No & Ambient temperature $\left({ }^{\circ} \mathrm{C}\right)$ & Load $(\mathrm{KN})$ & Swing frequency $(\mathrm{Hz})$ & Swing times \\
\hline $1 \#$ & 25 & 30 & 2.5 & 25000 \\
$2 \#$ & 55 & 30 & 2.5 & 25000 \\
$3 \#$ & 85 & 30 & 2.5 & 25000 \\
$4 \#$ & 115 & 30 & 2.5 & 25000 \\
$5 \#$ & 145 & 30 & 2.5 & 25000 \\
\hline
\end{tabular}

\subsection{Experiment method}

The friction and wear tests were carried out on the spherical plain bearing testing machine. Its structure is shown in Figure 3. The principle of the testing machine is to change the motor speed by the inverter to adjust the swing frequency of the spherical plain bearing, and the hydraulic system loads the spherical plain bearing. The testing machine can test 4 sets of bearings at the same time, and can real-time monitor and record the bearing wear, friction coefficient and friction temperature rise. During the test, the spherical plain bearing is firstly kept under heat and pressure for $30 \mathrm{~min}$, so that the test bearing reaches the specified ambient temperature and eliminates the influence of the initial deformation of the bearing. The load is $30 \mathrm{KN}$ (nominal contact pressure $\mathrm{p}=51.19 \mathrm{MPa}$ ) during pressure holding. Then set the swing angle to $\pm 6^{\circ}$ for the friction and wear test. The specific test plan is shown in Table 1. After the test, the surface of the worn liner and inner ring was micro-analyzed by LSCM-800 laser confocal scanning analyzer and energy dispersive spectrometer (EDS).

\section{Results and analysis}

\subsection{Effect of ambient temperature on tribological performance}

In the working process of the spherical plain bearings, the liner will be constantly worn out, and the thickness of the liner will gradually decrease. The wear amount of the spherical plain bearing liner is the decrease of the thickness of the liner, and it is also the variation of the radial displacement of the bearing. Therefore, the wear amount of the spherical plain bearing liner can be measured by measuring the variation of the outer ring by the displacement sensor. Figure 4 is an analysis result diagram of the wear amount of the spherical plain bearing liner under different environmental temperatures. It can be seen from the change curve of the amount of wear in Figure 4 that the wear of the liner can be divided into three stages under different environmental temperatures. The first stage is the running-in period. In this stage, the fibers are produced under the combined action of compressive stress and shear stress. The abrasive debris and transfer film are filled into the gaps and pits caused by weaving. The second stage is the plateau period. At this time, a complete transfer film has been formed on the surface of the liner. And the transfer film is consumed slowly and the wear rate is very low. The third stage is a period of rapid degradation, during which PTFE transfer films that reduce friction are almost depleted. A large number of aramid fibers are exposed to produce friction with the inner ring, and the aramid transfer film is formed through creep. This transfer film has a poor friction reduction effect.

Besides, by observing the liner wear curve at different ambient temperatures, it can be found that the duration of the three phases is different under different temperature conditions. Under the condition of $25^{\circ} \mathrm{C}$, the running-in period of the liner is about $60 \mathrm{~min}$ longer. At the end of the running-in period, the amount of wear is already large. This is caused by the slow friction reduction effect of the PTFE transfer film formed at the lower bearing temperature. When the ambient temperature is $55^{\circ} \mathrm{C}$, the running-in period of the bearing is shortened to about $40 \mathrm{~min}$, and then the wear rate of the liner is quickly reduced. However, due to the increase in temperature, the wear resistance of the PTFE transfer film decreases. When the wear rate of the liner in the plateau period is slightly greater than $25^{\circ} \mathrm{C}$, 


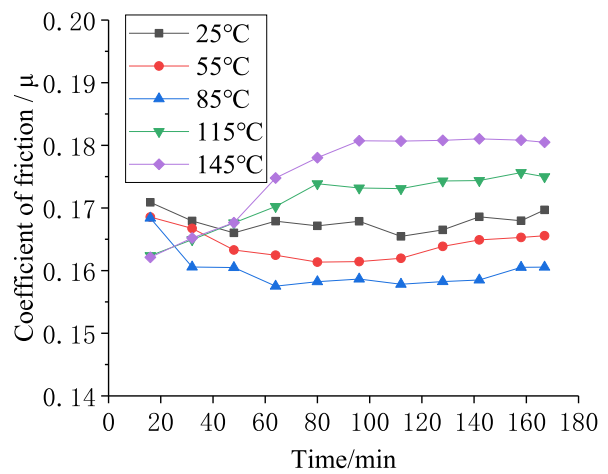

Fig. 5. Change process of friction coefficient.

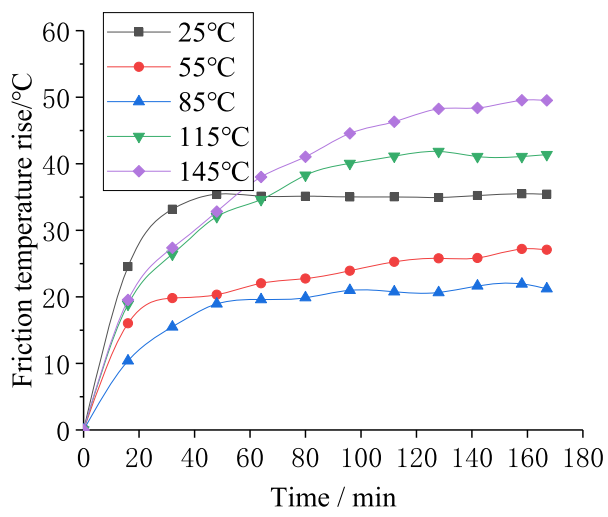

Fig. 6. Friction temperature rise process. the minimum wear amount at the end of the test is $0.049 \mathrm{~mm}$, which is $29.0 \%$ lower than that at $25^{\circ} \mathrm{C}$. When the ambient temperature is $85^{\circ} \mathrm{C}$, it shows the same pattern as $55^{\circ} \mathrm{C}$. As the ambient temperature continues to rise, when the temperature reaches $115^{\circ} \mathrm{C}$, the plateau period between the running-in period and the rapid degradation period of the liner wear is very short. When the ambient temperature increased to $145^{\circ} \mathrm{C}$, the degree of wear was accelerated, and the amount of wear at the end of the test was $0.091 \mathrm{~mm}$, which was an increase of $33.9 \%$ compared to the normal temperature of $25^{\circ} \mathrm{C}$.

Figure 5 shows the changing process of the friction coefficient of the spherical plain bearing under different ambient temperatures. It can be seen from the figure that in the initial stage, the friction coefficient is the largest at $25{ }^{\circ} \mathrm{C}$, and the friction coefficient shows a downward trend with the increase of the ambient temperature. It can be inferred that the increase in temperature can accelerate the creep of PTFE fibers to form a transfer film with a smaller friction coefficient. The time taken for the friction coefficient of the liner to enter the stationary phase is the same as the time when the wear enters the stationary phase. In the stationary phase, the loss of the PTFE transfer film is slow and can be replenished in time, so the friction coefficient tends to be stable. At the ambient temperature of $115-145^{\circ} \mathrm{C}$, the friction coefficient changes with time firstly increasing and then stabilizing. During the increase of the friction coefficient, the rate of consumption of the PTFE transfer film is greater than the rate of formation. When the PTFE fiber is not consumed enough to provide sufficient transfer film, the exposed aramid fiber begins to participate in friction, and creeps through the interaction with the inner ring to form an aramid transfer film with a large friction coefficient.

Figure 6 shows the analysis results of the friction temperature rise of spherical plain bearings under different ambient temperatures. It can be seen from the temperature rise curve that the bearing temperature rises rapidly in a short period time at various ambient temperatures. The bearing temperature rise quickly reaches a stable state when the ambient temperature is $25-85^{\circ} \mathrm{C}$, and the liner is at $25^{\circ} \mathrm{C}$. In the initial stage, the transfer film is formed slowly, and the bearing is a friction between the inner ring and the PTFE fiber and aramid fiber for a long period time. During this period, the friction coefficient is large and the temperature rises quickly. When the ambient temperature is $55-85^{\circ} \mathrm{C}$, the formation of PTFE transfer film is accelerated, and the temperature rise rate is effectively suppressed. When the ambient temperature is $115-145^{\circ} \mathrm{C}$, the PTFE transfer film consumes fast. With the bearing running, the PTFE transfer film is getting less and less, and the aramid transfer film is more and more, causing the friction coefficient to become larger and larger, resulting in an increased temperature rise. At the end of the test, the minimum friction temperature rise under $85^{\circ} \mathrm{C}$ working conditions is $21.23^{\circ} \mathrm{C}$, which is $42.9 \%$ lower than that at a normal temperature of $25^{\circ} \mathrm{C}$. At $14.5^{\circ} \mathrm{C}$, the maximum friction temperature rise is $49.52^{\circ} \mathrm{C}$, which is $39.7 \%$ higher than that at a normal temperature of $25^{\circ} \mathrm{C}$.

\subsection{LSCM analysis of the transfer film at different ambient temperatures}

The self-lubricating property of the liner self-lubricating spherical plain bearing is that the PTFE fiber in the liner produces cold flow under the combined action of compressive stress and shear stress to form a PTFE transfer film with a low friction coefficient. The friction between the large aramid fiber and the inner ring can also cover some hard particles to reduce the occurrence of abrasive wear.

Figure 7 is a micrograph of the wear surface of the liner and inner ring after the spherical plain bearing wears under different ambient temperatures. Figure 7 a shows that the PTFE transfer film (black) has evenly covered the surface of the liner at $25^{\circ} \mathrm{C}$, but the PTFE transfer film is thin and yellow aramid can also be seen. From Figure 7f, it can be seen that there is a small amount of transfer film on the surface of the inner ring, and there are obvious scratches along the direction of bearing rotation. It can be judged that the form of bearing wear is adhesive wear and abrasive wear. Figure $7 \mathrm{~b}$ is a microscopic view of the grinding surface under the condition of $55^{\circ} \mathrm{C}$. At this time, the PTFE transfer film on the friction surface of the liner is thick, and it is difficult to see the aramid through the PTFE transfer film. At the same time, the transfer film adhering to the inner ring surface increases, and the phenomenon of scratches is also more obvious. From Figure 7c, it can be seen that the thickness and uniformity of the PTFE transfer film formed on the surface of the liner at $85^{\circ} \mathrm{C}$ are both better than 25 and $55^{\circ} \mathrm{C}$, and there are few scratches 

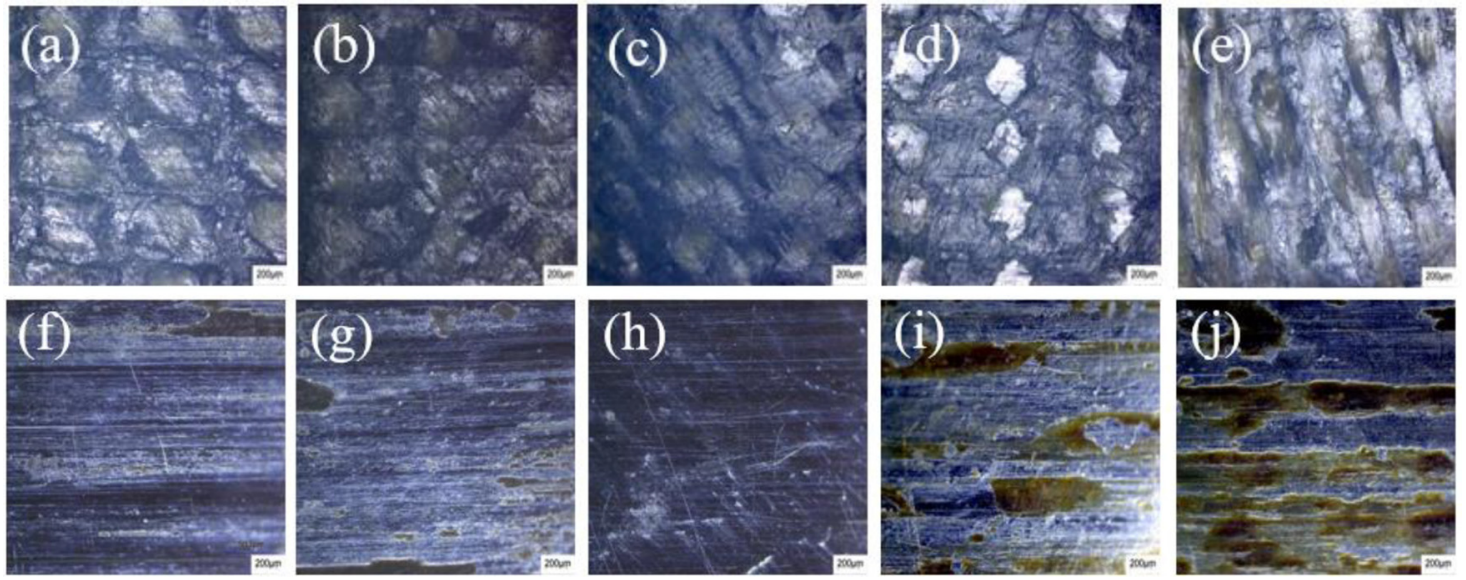

Fig. 7. LSCM diagram of spherical plain bearing after friction and wear (a-e is the wear surface of the liner at $25,55,85,115,145^{\circ} \mathrm{C}$; $\mathrm{f}-\mathrm{j}$ is the wear surface of the inner ring at $\left.25,55,85,115,145^{\circ} \mathrm{C}\right)$.

on the inner ring surface and the transfer film from the liner. This is because the high temperature reduces the attraction between the molecules in the PTFE, so that the degree of creep of the PTFE fiber increases. At an ambient temperature of $85^{\circ} \mathrm{C}$, the temperature of the bearing liner is close to $130^{\circ} \mathrm{C}$. PTFE has a second-order $\alpha$-transition at $130^{\circ} \mathrm{C}$. This $\alpha$-transition is most likely to promote the occurrence of the amorphous phase of PTFE, which forms the transfer film [26]. Figure $7 \mathrm{~d}$ is a micrograph of the liner at $115^{\circ} \mathrm{C}$ after abrasion. At this time, although the surface of the liner is covered with a large amount of PTFE transfer film, the consumption of the transfer film is obvious, and the aramid fiber has begun to participate in friction. From the surface of the inner ring in Figure 7i, it can be seen that the furrow phenomenon is more serious, and there is a large area of yellow adhesive, which is a transfer film after the creep of aramid, which causes an increase in the friction coefficient. Figure 7e is a microscopic view of the friction surface at $145^{\circ} \mathrm{C}$. At this time, the PTFE transfer film on the surface of the liner is almost consumed. The aramid fiber undergoes creep to produce a large number of transfer films, scratches are produced on the corresponding inner ring surface and a large number of aramid transfer films have adhered. The form of bearing wear becomes severe abrasive wear and adhesive wear.

The micrograph of the liner after gray-scale and binarization by metal metallographic analysis software is shown in Figure 8 . The red line in Figure 8 is the boundary line of the PTFE transfer film, and the black area is the PTFE transfer film. The percentage of the area of the black area to the total image area is the liner transfer film coverage.

Figure 9 shows the analysis results of the transfer film coverage of the liner friction surface under different ambient temperatures. It can be seen from Figure 9 that as the ambient temperature increases, the coverage of the PTFE transfer film increases first and then decreases. At $85^{\circ} \mathrm{C}$, the maximum coverage is $92.2 \%$, which is an increase of $29.4 \%$ compared to $25^{\circ} \mathrm{C}$. When the tempera-

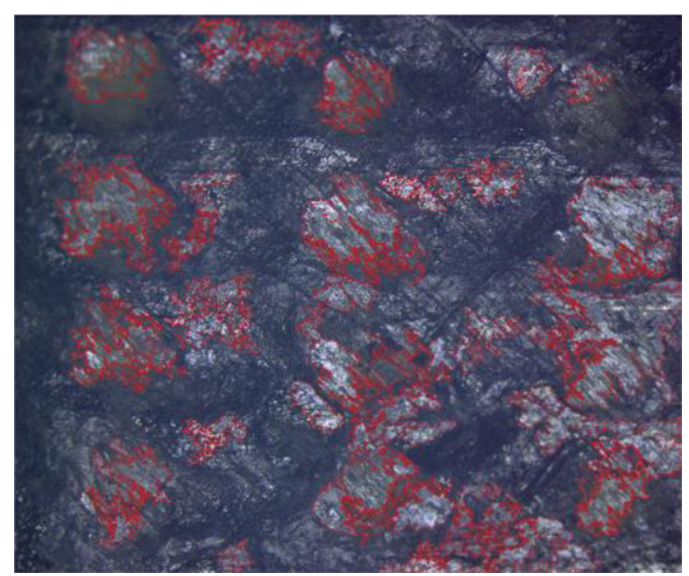

Fig. 8. Micrograph of the liner after binarization.

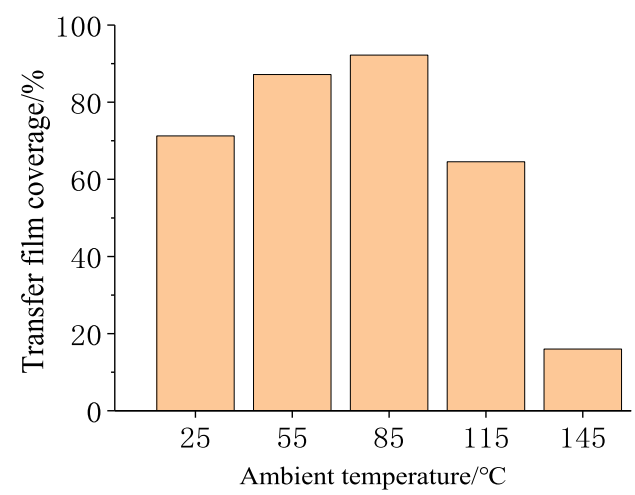

Fig. 9. Coverage of PTFE transfer film on the surface of the liner.

ture rises above $115{ }^{\circ} \mathrm{C}$, the coverage of PTFE transfer film drops rapidly. Especially at $145^{\circ} \mathrm{C}$, the coverage of PTFE transfer film is only $16 \%$, which is $77.5 \%$ lower than that of normal temperature. Figure 10 shows the effect of PTFE transfer film coverage on the tribological performance. 
It can be seen from the figure that the anti-friction effect of the spherical plain bearing is positively related to the PTFE transfer film coverage. The greater the coverage of the PTFE transfer film, the lower the friction coefficient and friction temperature rise of the bearing. However, with the increase of the coverage of PTFE transfer film, the wear amount showed a trend of first decreasing and then increasing. When the PTFE transfer film coverage reaches $87 \%$, the wear amount is the smallest, and when it reaches $92 \%$, the wear amount increases slightly. According to the test conditions, it can be seen that when the coverage of the PTFE transfer film is $92 \%$, the corresponding ambient temperature is $85^{\circ} \mathrm{C}$, and when the coverage of the transfer film is $87 \%$, the corresponding ambient temperature is $55^{\circ} \mathrm{C}$. Therefore, the increase in the amount of wear is caused by the increase in temperature which reduces the wear resistance of the PTFE transfer film.

\subsection{EDS analysis of transfer membranes at different ambient temperatures}

To analyze the changes in the composition and content of the friction surface transfer film under different environments

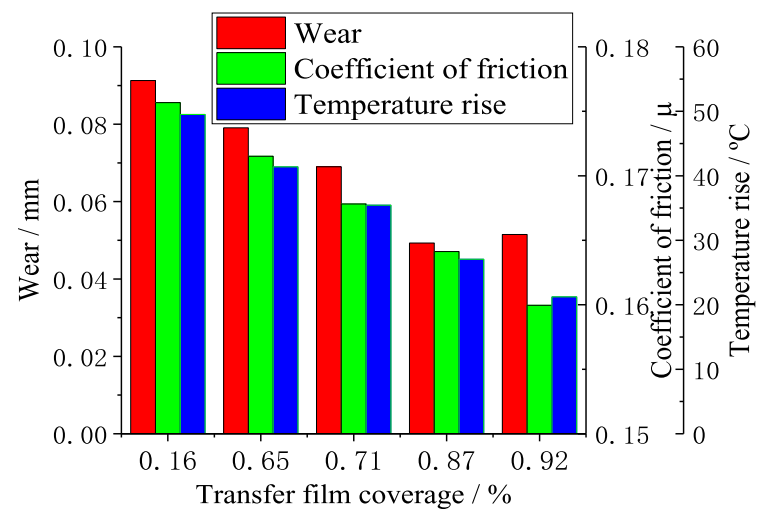

Fig. 10. Effect of transfer film coverage on tribological performance. and temperatures, quantitative analysis was performed on PTFE characteristic element F, aramid characteristic element $\mathrm{N}$, and inner ring marking element Cr. Figure 11a is the element content of the inner ring surface. It can be seen from the figure that the $\mathrm{N}$ element mass fraction shows a trend of decreasing first and then increasing with the increase of the ambient temperature. It is a minimum of $0.05 \%$ at $85^{\circ} \mathrm{C}$ and a maximum of $27.96 \%$ at $145^{\circ} \mathrm{C}$. At 55 and $115^{\circ} \mathrm{C}$, the two peaks of the $\mathrm{F}$ element mass fraction are $13.71 \%$ and $7.71 \%$. It can be inferred that the adhesion on the inner ring surface is mainly aramid transfer film at $25^{\circ} \mathrm{C}$, and the content of PTFE transfer film and aramid transfer film at 55 and $85^{\circ} \mathrm{C}$ are equivalent. At 115 and $145^{\circ} \mathrm{C}$, the inner ring surface transfer film is mainly aramid.

The influence rule of the ambient temperature on the mass fraction of the marking elements on the liner is shown in Figure 11b. From the figure, it can be seen that the $\mathrm{Cr}$ element content on the liner surface is the highest at $55{ }^{\circ} \mathrm{C}$, but only $4.87 \%$. The mass fraction of the $\mathrm{N}$ element showed a tendency to decrease first and then increase with the increase of the ambient temperature. At $85^{\circ} \mathrm{C}$, it was at least $7.9 \%$, and at $145^{\circ} \mathrm{C}$, it reached $18.78 \%$. The change rule of $\mathrm{F}$ element content is the opposite, the mass fraction exceeds $20 \%$ at 55 and $85^{\circ} \mathrm{C}$, and at least $8.35 \%$ at $145^{\circ} \mathrm{C}$. Besides, the $\mathrm{N}$ element content is less than the $\mathrm{F}$ element when the ambient temperature is $25-115^{\circ} \mathrm{C}$, and the $\mathrm{N}$ element content exceeds the $\mathrm{F}$ element when the ambient temperature is $145^{\circ} \mathrm{C}$. It can be seen that the content of the PTFE transfer film formed on the surface of the liner shows a trend of increasing after the ambient temperature increases, and the transfer film is mainly PTFE transfer film at $25-115^{\circ} \mathrm{C}$, and the aramid transfer film is the main transfer film at the ambient temperature of $145^{\circ} \mathrm{C}$.

The reason for the above phenomenon is that when the ambient temperature is low, the degree of the cold flow of PTFE is low, and a large area of transfer film cannot be quickly formed, so that aramid fiber participates in friction.

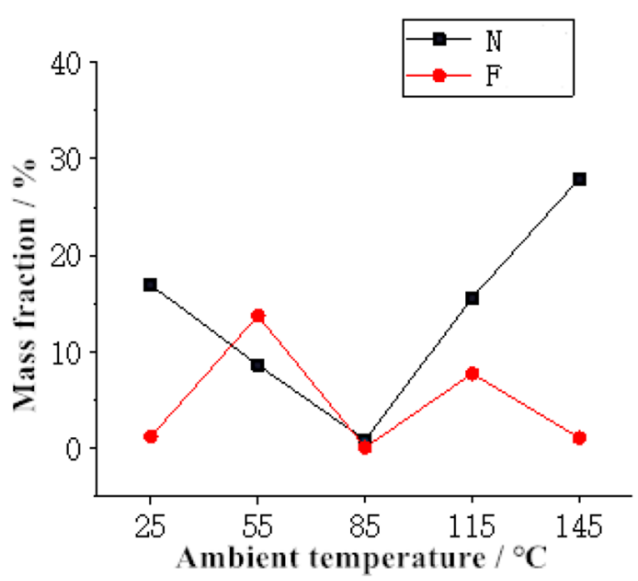

(a)

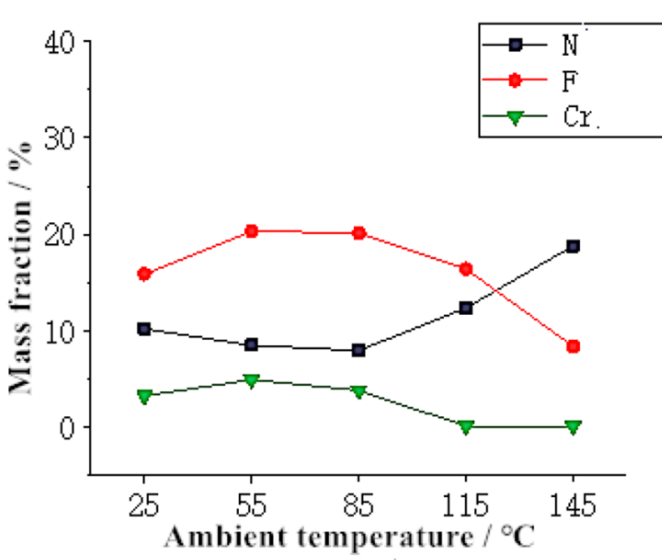

(b)

Fig. 11. Characteristic element content of the transfer film on the friction surface. (a) Inner ring (b) Liner. 
When the ambient temperature rises, the degree of PTFE cold flow is accelerated, which can quickly form a large-area transfer film, which prevents aramid from participating in friction, but the high ambient temperature accelerates the consumption of PTFE.

\section{Conclusion}

With the increase of ambient temperature, the amount of wear, the average coefficient of friction, and the temperature rise of friction all show a trend of decreasing first and then increasing. The amount of wear is the smallest at $55^{\circ} \mathrm{C}$, which is $29.0 \%$ lower than the normal temperature of $25^{\circ} \mathrm{C}$. The friction coefficient and friction temperature rise are the smallest at $85^{\circ} \mathrm{C}$, which is $4.8 \%$ and $42.9 \%$ lower than the normal temperature of $25^{\circ} \mathrm{C}$.

The wear forms of spherical plain bearings under different environmental temperatures are mainly adhesive wear and abrasive wear. As the ambient temperature increases, the degree of abrasive wear and adhesive wear decreases first and then increases. The scratches caused by abrasive wear can induce adhesive wear.

When the ambient temperature is $25-115^{\circ} \mathrm{C}$, the PTFE transfer film is the main transfer film on the liner surface, and the aramid transfer film is the main one at $145^{\circ} \mathrm{C}$. The tribological performance during the operation of the spherical plain bearing is positively related to the coverage of the PTFE transfer film. The formation and consumption of the PTFE transfer film form three stages of spherical plain bearing wear. The ambient temperature affects the service life of the liner spherical plain bearing by affecting the formation and consumption time of the PTFE transfer film.

The authors are grateful for financial support from the National Natural Science Foundation of China (Grant No. 51275155).

\section{References}

[1] J. Aguirrebeitia, M. Abasolo, J. Vallejo, I. Coria, I. Heras, Methodology for the assessment of equivalent load for selflubricating radial spherical plain bearings under combined load, Tribol. Int. 105, 69-76 (2017)

[2] X.J. Shen, L. Cao, Y.G. Chen, R.Y. Li, Research status and prospect of spherical plain bearings with self-lubricating fabric liner, Bearing 3, 57-61 (2009)

[3] X.G. Shen, Y.F. Liu, L. Cao, X.Y. Chen, Numerical simulation of sliding wear for self-lubricating spherical plain bearings, J. Mater. Res. Technol. 1, 8-12 (2012)

[4] B.C. Kim, D.G. Lee, Endurance and performance of a composite spherical bearing, Compos. Struct. 87, 71-79 (2008)

[5] M. Qiu, J.J. LU, Y.C. Li, G.S. Lv, Investigation on MoS2 and graphite coatings and their effects on the tribological properties of the radial spherical plain bearings, Chin. J. Mech. Eng. 29, 844-852 (2016)
[6] M. Qiu, Z.P. Yang, J.J. Lu, Y.C. Li, D.W. Zhou, Influence of step load on tribological properties of self-lubricating radial spherical plain bearings with PTFE fabric liner, Tribol. Int. 113, 344-353 (2017)

[7] M. Qiu, Z.G. Li, Y.C. Li, L. Chen, Y.W. Li, Effect of liner modification on the tribological properties of self-lubricating spherical plain bearings under tilting oscillation, Tribology 34, 59-64 (2014)

[8] Z.Q. Hu, W. Li, Y.L. Yang, B.L. Fan, H.L. Zhou, Thermal error compensation of the wear-depth real-time detecting of self-lubricating spherical plain bearings, Chin. J. Mech. Eng. 31, 28-40 (2018)

[9] S. Pal, R. Sarkar, V. Jayaram, Characterization of Thermal Stability and High-Temperature Tribological Behavior of Electroless Ni-B Coating, Metall. Mater. Trans. A 49, 3217-3236 (2018)

[10] H.J. Zhang, Z.Z. Zhang, F. Guo, K. Wang, W. Jiang, Enhanced wear properties of hybrid PTFE/cotton fabric composites filled with functionalized multi-walled carbon nanotubes, Mater. Chem. Phys. 116, 183-190 (2009)

[11] F.H. Su, Z.Z. Zhan, W.M. Liu, Tribological behavior of hybrid glass/PTFE fabric composites with phenolic resin binder and nano-TiO2 filler, Wear. 264, 562-570 (2008)

[12] B.A. Krick, J.J. Ewin, G.S. Blackman, C.P. Junk, W.G. Sawyer, Environmental dependence of ultra-low wear behavior of polytetrafluoroethylene (PTFE) and alumina composites suggests tribochemical mechanisms, Tribol. Int. 51, 42-46 (2012)

[13] S. Bahadur, D. Tabor, The wear of filled polytetrafluoroethylene, Wear 98, 1-13 (1984)

[14] A. William, H. Donald, Adhesion and friction of PTFE in contact with metals as studied by Auger spectroscopy, field ion and scanning electron microscopy, Wear 26, 75-93 (1973)

[15] A.A. Pitenis, J.J. Ewin, K.L. Harris, In vacuo tribological behavior of polytetrafluoroethylene (PTFE) and alumina nanocomposites: the importance of water for ultralow wear, Tribol. Lett. 53, 189-197 (2014)

[16] L. Ding, D. Axinte, P. Butler-Smith, A.A. Hassan, Study on the characterisation of the PTFE transfer film and the dimensional designing of surface texturing in a drylubricated bearing system, Wear 448-449, 203238 (2020)

[17] Y.X. Wang, H.L. Wang, F.Y. Yan, The study of correspondence on tribology of PTFE composites and its transfer films, China Surf. Eng. 22, 49-53 (2009)

[18] Y.L. Yang, X.M. Fang, F. Wu, Research on wear performance of self-lubricating spherical plain bearings, Bearing 12, 38-41 (2015)

[19] H.J. Zhang, Z.Z. Zhang, F. Guo, Studies of the influence of graphite and MoS2 on the tribological behaviors of hybrid PTFE/Nomex fabric composite, Tribol. Trans. 54, 417-423 (2011)

[20] R.K. Goyal, M. Yadav, Study on wear and friction behavior of graphite flake-filled PTFE composites, J. Appl. Polym. Sci. 127, 3186-3191 (2013)

[21] S.C. Yan, Y.L. Yang, L.Z. Song, X.W. Qi, Z. Zuo, Y.X. Xue, Tribological property of 3-aminopropyltriethoxysilanegraphite oxide nanosheets reinforced polyethersulfone composite under drying sliding condition, Tribol. Int. 103, 316-330 (2016)

[22] A.A. Pitenis, K.L. Harris, C.P. Junk et al., Ultralow Wear PTFE and Alumina Composites: It is All About Tribochemistry, Tribol. Lett. 57, 1-8 (2015) 
[23] R. Rattan, J. Bijwe, M. Fahim, Influence of weave of carbon fabric on low amplitude oscillating wear performance of polyetherimide composites, Wear 262, 727-735 (2006)

[24] R. Rattan, J. Bijwe, Carbon fabric reinforced polyetherimide composites: Influence of weave of fabric and processing parameters on performance properties and erosive wear, Mat. Sci. Eng. A 420, 342-350 (2006)
[25] M.T. Demirci, H. Düzcükoglu, Wear behaviors of Polytetrafluoroethylene and glass fiber reinforced Polyamide 66 journal bearings, Mater. Design. 57, 260-269 (2014)

[26] N. Dusunceli, O.U. Colak, Modelling effects of degree of crystallinity on mechanical behavior of semicrystalline polymers, Int. J. Plasticity. 24, 1224-1242 (2007)

Cite this article as: M. Qiu, K.-W. Tian, Y.-T. Zhang, Effect of ambient temperature on the formation mechanism of PTFE liner transfer film of spherical plain bearings, Mechanics \& Industry 22, 11 (2021) 